\title{
ESTUDO DE POTENCIAIS DOADORES NOTIFICADOS E CAPTAÇÃO DE ÓRGÃOS EM UM HOSPITAL ESTADUAL NO RIO DE JANEIRO
}

\author{
Study of potential organ retrieval and notification of a state hospital in Rio de Janeiro
}

\author{
Daniel Ribeiro Soares de Souza
}

\section{RESUMO}

Objetivo: Descrever os indicadores de desempenho relacionados à notificação de mortes encefálicas e captação de órgãos em relação aos óbitos ocorridos na Unidade de Terapia Intensiva (UTI/sala amarela) do Hospital Estadual Getulio Vargas (HEGV), entre o período de janeiro a setembro de 2010. Métodos: Trata-se de um estudo descritivo quantitativo retrospectivo. Foram estudados os prontuários de pacientes internados no CTI e sala amarela do HEGV entre os meses de janeiro a setembro de 2010. Resultados: Durante o período de janeiro a setembro de 2010, a Central de Transplantes recebeu ao todo, 364 notificações de ME de todos os hospitais pertencentes ao Estado do Rio, independente de sua esfera administrativa (federal, estadual, municipal e particular). O Hospital Estadual Getúlio Vargas foi responsável por 32 dessas notificações, representando $8,8 \%$ do total e tem se mostrado fundamental para a melhoria desses números no estado. Individualmente, encontra-se acima da média de efetivações de doação, com 46,4\%, quando o esperado pela Associação Brasileira de Transplante de Órgãos (ABTO) é 40\%. Conclusão: Acredita-se que, com maior treinamento de profissionais, criação de CIHDOTT's com profissionais exclusivos para busca ativa, manutenção do potencial doador e entrevista familiar, os índices de notificação, captação e efetivação de doação poderão elevar as estatísticas dos transplantes no estado do Rio de Janeiro.

Descritores: Doação de Órgão; Transplantes; Mortalidade.

Instituição:

Unidade de Pós-Operatório Neurovascular do Hospital Estadual Getúlio Vargas,

Rio de Janeiro/RJ

\author{
Correspondência: \\ Daniel Ribeiro Soares de Souza \\ Rua Dois de Fevereiro, 576, casa 14 / 201, CEP 20730-452, Engenho de Dentro, \\ Rio de Janeiro/RJ \\ Tel: (21) 7872-5365 \\ Email: danielribeiroenf@hotmail.com
}

Recebido em: 25.05.2011

Aceito em: 30.06 .11

\section{INTRODUÇÃO}

O conceito de morte não é estanque, embora as funções cardíacas e pulmonares sejam reconhecidas há séculos como essenciais para a sobrevivência. Com o avanço dos estudos, das técnicas de ressuscitação e de suporte vital, a atividade cerebral veio definir a vida e a morte do indivíduo, vinculando a morte a critérios neurológicos e evoluindo para o que conhecemos atualmente como Morte Encefálica (ME). ${ }^{1}$

A determinação da ME varia de país para país. No Brasil, o Conselho Federal de Medicina, Resolução CFM (Conselho Federal de Medicina) no 1.480/97, define morte encefálica como estado irreversível de cessação de todo o encéfalo e funções neurais, considerando tanto os hemisférios cerebrais como o tronco encefálico, resultante de edema e maciça destruição dos tecidos encefálicos, apesar da atividade cardiopulmonar poder ser mantida por avançado sistema de suporte vital e mecanismos de ventilação. ${ }^{2,3}$

Inicialmente, deve ser definida a causa do coma para que se possa declarar que um paciente esteja em ME. As causas mais freqüentes são: o traumatismo crânio-encefálico (TCE), no contexto de acidentes automobilísticos ou agressões; hemorragia subaracnóidea, ligada à ruptura de aneurisma; lesão difusa do cérebro após parada cardiorrespiratória revertida; hemorragia cerebral espontânea maciça; grandes lesões isquêmicas e, em menor número, as meningoencefalites e encefalites fulminantes e a falência hepática aguda (por hepatite viral ou tóxica ou raramente, Síndrome de Reye). ${ }^{4}$

O diagnóstico de ME é determinado pelo exame clínico 
neurológico, a partir da ausência evidente de reflexos do tronco cerebral em um paciente em coma, excluída qualquer causa reversível deste, tais como: intoxicação exógena, uso terapêutico de barbitúricos, alterações metabólicas e hipotermia.

Durante as últimas três décadas, o transplante de órgãos evoluiu de um procedimento complexo, pouco conhecido e arriscado para uma conduta eficaz e segura. Como conseqüência, um crescente número de pacientes aguarda o transplante de órgão como opção ao tratamento das doenças crônicas e terminais de rim, fígado, coração, pâncreas e pulmão.

Assim, se por um lado os transplantes de órgãos e tecidos no Brasil alcançam resultados comparáveis aos dos países mais ricos do mundo, o número de procedimentos realizados permanece aquém das necessidades assistenciais. ${ }^{5} \mathrm{~A}$ taxa real de potenciais doadores identificada em 2005 em diferentes países variou de 35 a 65 doadores/milhão de pessoas por ano (pmp/ano), taxa inferior à apontada nos estudos teóricos que calculam o possível número de potenciais doadores, que varia de 100 a 150 pmp/ano. ${ }^{6}$ Uma estimativa aceitável seria de uma taxa entre 50-60 doadores pmp/ano, uma vez que destes, somente $15 \%$ a $67 \%$ tornam-se doadores efetivos devido à não detecção ou não notificação de morte encefálica, às contra-indicações médicas, aos problemas de manutenção dos doadores (15 a 40\%) ou à recusa familiar (20 a $50 \%)^{7,8}$ No Brasil, apesar deste ser o país mais populoso da América Latina, vive-se atualmente uma triste marca, com um número efetivo de doação de órgãos de doador falecido de 7,2 por milhão de habitantes ao ano (pmp/ano), ficando atrás de países como Uruguai (24,9 pmp/ano), Argentina (11,7 pmp/ano), Colômbia (9,9 pmp/ano) e Chile (9,8 pmp/ano). ${ }^{9}$

No primeiro semestre de 2009, o Estado do Rio de Janeiro ocupava o $7^{\circ}$ lugar entre os estados brasileiros no que se refere à potencialidade da doação (33,4 ppm/ano). Entretanto, nas doações efetivas, ocupava o $12^{\circ}$ lugar, com uma taxa de 4,4 ppm/ano, efetivando apenas $13,1 \%$ de suas notificações. ${ }^{10}$

\section{OBJETIVOS}

\section{Geral}

Descrever os indicadores de desempenho relacionados à notificação de mortes encefálicas e captação de órgãos em relação aos óbitos ocorridos na Unidade de Terapia Intensiva (UTI/sala amarela) do Hospital Estadual Getulio Vargas (HEGV-RJ) entre o período de janeiro a setembro de 2010.

\section{Específicos}

- Identificar o potencial do HEGV em captação de órgãos, perante seu perfil referencial no estado do Rio de Janeiro;

- Analisar o perfil dos óbitos potenciais para captação de órgãos ocorridos no CTI e sala amarela HEGV;

\section{MÉTODOS}

Trata-se de um estudo descritivo quantitativo retrospectivo. Foram estudados os prontuários dos pacientes internados no CTI e na sala amarela do HEGV entre os meses de janeiro a setembro de 2010. A identificação dos prontuários foi realizada pelo livro de Relatório Geral do setor, com comparação ao Livro de Notificações da Central de Transplantes do Estado do Rio de Janeiro. Como critérios de exclusão, foram eliminados os prontuários que se apresentavam ilegíveis ou com informações incompletas em relação ao diagnóstico do paciente.

O perfil dos óbitos nas unidades foi estratificado em relação aos seguintes itens: morte encefálica X morte PCR. Ainda, sobre o quantitativo de morte por causas neurológicas, foram estratificadas as principais causas de morte; doações efetivas $\mathrm{X}$ doações não efetivas.

Os dados estatísticos foram analisados pelo programa estatístico Epi Info versão. ${ }^{3.11}$

\section{RESULTADOS}

Durante o período de janeiro a setembro de 2010, a Central de Transplantes recebeu 364 notificações de ME, entre todos os hospitais pertencentes ao Estado do Rio, independente de sua esfera administrativa (federal, estadual, municipal e particular). O Hospital Estadual Getúlio Vargas foi responsável por 32 dessas notificações, representando $8,8 \%$ do total.

Em relação ao número de doações efetivas, o Estado do Rio de Janeiro efetivou 61 doações nesse mesmo período, sendo o HEGV responsável por 13 dessas efetivações (21,3\%) (Figura 1). Desta forma, concluímos que a taxa de efetivação (razão entre as doações efetivas e notificações viáveis) da doação estadual encontra-se em $16,7 \%$, enquanto a referida taxa no HEGV encontra-se em $46,4 \%$.

\section{DISCUSSÃO}

O aumento significativo de notificações e doações efetivas, nos meses de julho, agosto e setembro, pode ser associado à nova política implementada pela Central de Transplantes do Rio de Janeiro, que disponibilizou seus funcionários, alocando-os nos hospitais de maior referência para emergências no estado.

Figura 1 - Evolução das notificações de morte encefálica e doações efetivas no Estado do Rio de Janeiro e do Hospital Estadual Getúlio Vargas - janeiro a setembro/2010

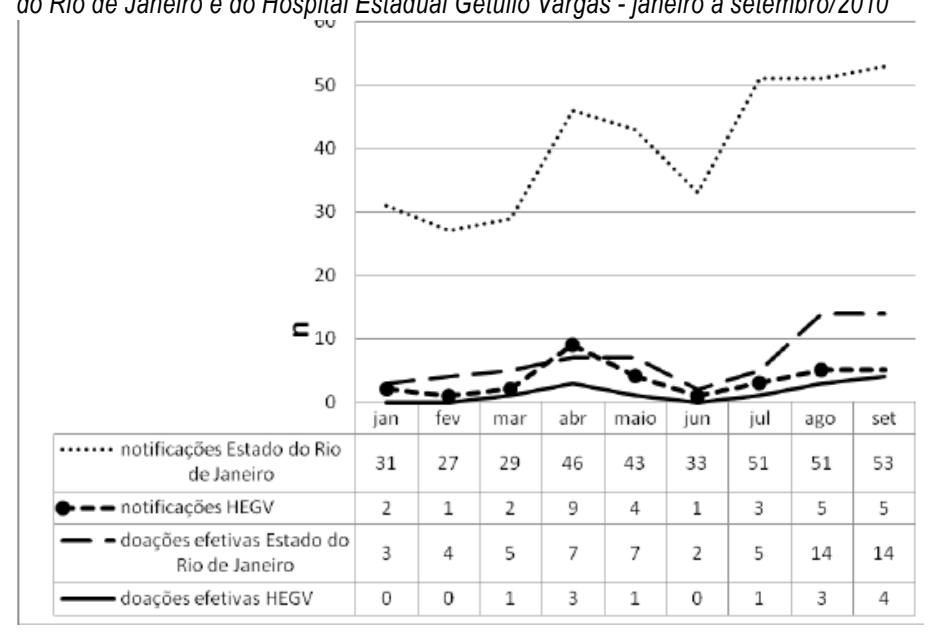

Fonte: Livro de Notificações e Doações, Central de Transplantes - RJ

Sobre a potencialidade do Hospital Estadual Getúlio Vargas para a captação de órgãos, os dados são significativos. Dentre as causas de óbitos nas unidades estudadas, 37,4\% são de causas neurológicas (Figura 2), sendo descritas respeitando o critério de diagnóstico de entrada na unidade. Dessas causas, a maior freqüência das notificações foi o acidente vascular hemorrágico intraparenquimatoso $(n=16)$ seguido do TCE $(n=8)$ e da hemorragia subaracnóide $(\mathrm{n}=6)$ (Figura 3). 
Figura 2 - Relação entre óbitos totais e óbitos por causas neurológicas - Unidade de Cuidados Intensivos I e II do Hospital Estadual Getúlio Vargas - Janeiro a Setembro/2010

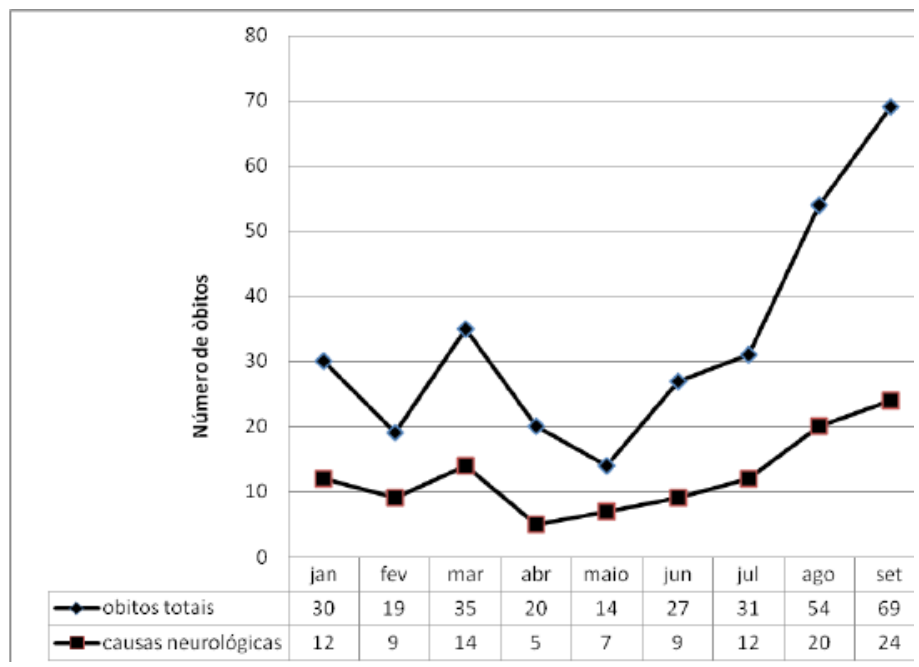

Fonte: Livro de Relatório Geral UCI I e UCI II - HEGV

\section{CONCLUSÃO}

Ainda há muito para se evoluir no Brasil em relação à captação de órgãos e transplantes. O Estado do Rio de Janeiro ainda não corresponde nesse quesito à sua força dentro da representatividade nacional, mas vem tentando mudar esse quadro. A criação do PET (Programa Estadual de Transplantes) é um sinal de esforço governamental na tentativa de melhoria. O Rio de Janeiro ainda está muito aquém das metas estabelecidas pela Associação Brasileira de Transplantes de Órgãos (ABTO) que é de 10 doadores ppm. O Hospital Estadual Getúlio Vargas tem se mostrado fun damental para a melhoria desses números no e stado e, individualmente,
Figura 3 - Causas dos óbitos notificados pelo Hospital Estadual Getúlio Vargas à Central de Transplantes - Janeiro a Setembro/2010

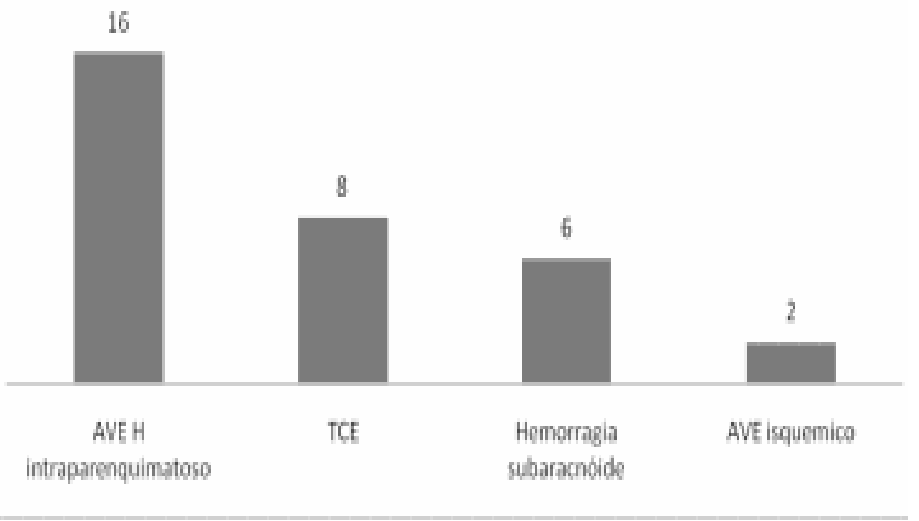

Fonte: Livro de Notificações e Doações, Central de Transplantes - RJ encontra-se acima da média de efetivações de doação, com $46,4 \%$, quando o esperado pela ABTO é de $40 \% .11$ Este fato pode ser atribuído ao treinamento adequado de alguns profissionais, ao comprometimento das chefias de unidades-chaves com o processo e à implementação de política de busca ativa da Central de Transplante mais intensa. Acredita-se que, com um maior treinamento de profissionais, criação de CIHDOTT's com profissionais exclusivos para busca ativa, manutenção do potencial doador e entrevista familiar, possam ser elevados os índices de notificação, captação e efetivação de doação e transplantes no estado do Rio de Janeiro.

\section{ABSTRACT:}

Purpose: To describe performance markers related to the notification of brain death and captation of agencies in relation to deaths occurred in the Intensive Care Unit of Hospital Getulio Vargas (HEGV-RJ) from January to September of 2010. Methods: Quantitative retrospective analysis on a descriptive study. Patients' records interned in the UCI of the HEGV between January and September, 2010 were analyzed. Results: From January to September, 2010, the Central Transplantation Office received 364 notifications of brain death. Hospital Getúlio Vargas was responsible for 32 of these notifications, representing $8.8 \%$ of the total. Hospital Getúlio Vargas has been shown to be fundamental for the improvement of these numbers in the state. Solely, that hospital is above the average of effective donations with $46.4 \%$, when the average expected by ABTO is $40 \%$. Conclusion: It is believed that with a higher training of professionals and having exclusive professionals in the active search, maintenance of the potential donor and interviewing families, such amount of notifications, retrieval and effective donations will increase the statistics of transplants in the state of Rio De Janeiro.

Keywords: Directed Donation; Transplantation; Mortality. 


\section{REFERÊNCIAS:}

1. Guetti NR, Marques IR. Assistência de enfermagem ao potencial doador de órgãos em morte encefálica. Rev Bras Enferm. 2008 jan-fev;61(1):91-7

2. Conselho Federal de Medicina.Resolução no. 1.480/97. Regulamentação do diagnóstico de morte encefálica.

3. Associação de Medicina Intensiva Brasileira. Morte encefálica. Curso de imersão em terapia intensiva neurológica. $4^{\mathrm{a}}$ ed. São Paulo (SP): AMIB; 2005.

4. André C, Morte cerebral- diagnóstico e suporte clínico. In: André C,Freitas GR. Terapia intensiva em neurologia e neurocirurgia - métodos de monitorização e situações especiais. Rio de Janeiro (RJ): Revinter; 2002. p. 303-23.

5. Schelemberg AM, Andrade J, Boing AF Notificações de mortes encefálicas à Central de Notificação, Captação e Distribuição de Órgãos e Tecidos. Arquivos Catarinenses de Medicina. 2007;36(1):30-36

6. Balupuri S, Buckley P, Snowden C, Sen MMB, Griffiths P, Hannon M, et al The trouble with kidneys derived from the non heart-beating donor: a single center 10 year experience. Transplantation. 2000 mar 15;69(5):842-6.
7. Werkman HA, Pruim J, Verget EMt, Duis HJt, Slooff MJH. Organ donation from trauma victims. Transplant Proc. 1991;23(5):2553-4.

8. Gore SM, Hinds CJ, Rutherford AJ. Organ Donation from intensive care units in England. BMJ. 1989;299:1193-7.

9. Associação Brasileira de Transplantes de Órgãos A. Dados gerais. RegistroBr asileiro de Transplantes. 2008 Jan-Dez;XIV [acesso em 20 de Novembro de 2010] Disponível em: www.abto.org.br

10. Registro Brasileiro de Transplantes. Dados Gerais. Ano XV - no 4 - Janeiro/ Dezembro 2009. [acesso em 20 de Novembro de 2010] Disponível em: www.abto.org.br

11. Registro Brasileiro de Transplantes. Dados Gerais. Ano XVI - no 4 - Janeiro/ Dezembro 2010. [acesso em 20 de Novembro de 2010] Disponível em: www. abto.org.br 